\title{
Development and performance evaluation of a high velocity burner for furnace operations
}

\author{
O.A. Ighodalo, C.I. Ajuwa and B.R. Iredje \\ Mechanical Engineering Department \\ Ambrose Alli University, Ekpoma
}

\begin{abstract}
Burners are very important in the metal processing industries where they are used for a variety of purposes. A high velocity burner is developed and tested. The main components of the burner include the burner nozzle, mixing tube, down-stream section and the throat. A cross-connected Regulator is also incorporated for air fuel ratio control. An open-air test was carried out on the burner and flame temperature values were taken along the axial flame axis for different gas pressures. From the test carried out, the highest temperatures recorded were 488.1, 688.8 960.3 and $1275{ }^{\circ} \mathrm{C}$ for gas pressures maintained at $30,60,90$ and $100 \%$ corresponding to $0.53,1.02$, 1.53 and 1.7 bar respectively.

The results show that the burner can be used for high temperature Furnace applications.
\end{abstract}

Keywords: Burner, Flame, Temperature, Test

\section{INTRODUCTION}

A Burner is a device that is used to combust a mixture of fuel and oxidizer, thus converting the chemical energy in the fuel into thermal energy (Buakal et al, 2001). The thermal energy or heat so generated is usually transferred to some type of load. Different types of burner designs are produced based on such factors as type of fuel, oxidizer, and combustion chamber geometries; environmental regulations, thermal input and heat transfer requirements which include flame temperature, flame momentum, and heat distribution. A given combustion system may have a single burner or many burners, depending on the size and type of the application. It is usually important to match the burner to the load so as to ensure maximum heat transfer and system thermal efficiency. This impacts positively on operating costs and pollutant emissions, giving a reduction, since less fuel needs to be combusted for a given production rate. When the outlet port of a burner is sized to provide an exit velocity exceeding $90 \mathrm{~m} / \mathrm{s}$ to the combustion products passing through it, such a burner becomes a high velocity burner (Baukal, 2004).

Burners are a key component in industrial combustion applications such as in metals, minerals and chemicals production and processing, waste incineration, steam generation in boilers, power generation and industrial drying processes. A classification by type of fuel gives solid, liquid or gaseous fuel-fired burners. The type of draft employed give rise to forced draft and natural draft burners, while pre-mixed and diffusion burners are so named because of the type of mixing of fuel and oxidizer. Air-fuel and oxy-fuel burners are burner types based on the type of oxidizer used (Baukal, 2004).

The aim of the present work is to develop and test a gaseous fuel, pre-mixed type burner which employs forced draft in mixing the fuel and the air. The test will determine the functionality of the burner.

\section{Design Analysis for the Burner:}

The Burner is venturi-shaped and consists of the inlet, throat, mixing tube, down stream section and the tip or nozzle each of which play a major role in the performance of the burner.

The expressions for the burner heat release and fuel gas mass flow rate are as given by Baukal (2004).

Burner Heat Release: The Burner heat release or the burner output power is determined from the expression:

$H R=m H V$

(1)

where, HR is the burner heat release, $m$ is the mass flow rate of the fuel, and HV is the heating value of the fuel.

Fuel gas flow rate: The fuel gas flows through an orifice and the flow rate depends on the flow 
condition whether it is sonic or subsonic. The fuel flow condition at the orifice is determined by the critical pressure ratio which is given by:

$$
P_{C}=\left[\frac{2}{k+1}\right]^{k /(k-1)}
$$

where $P_{c}$ is the critical pressure ratio and $k$ is the ratio of specific heats of the fuel.

If $P_{C_{t}}>$ $P_{b} / P_{t}$, then the fuel exits the orifice at sonic conditions. If $P_{c}<P_{b} / P_{c}$, then the fuel exits the orifice at subsonic conditions. $P_{b}$ and $P_{t}$ are absolute values of atmospheric and fuel pressures respectively.

Hence, for sonic conditions the mass flow of the fuel through the orifice is given by:

$$
m=\frac{c_{d} P_{t} g_{c} A}{\sqrt{T_{t} R g_{c} / M W}} k^{\frac{1}{2}}\left[\frac{2}{k+1}\right]^{\frac{k+1}{2(k-1)}}
$$

where $c_{d}$ is the orifice discharge coefficient which ranges from 0.75 to $0.95, A$ is the area of the orifice. $T_{t}$ is the temperature of the fuel gas, $R$ is the universal gas constant which is equal to 8314.34 $\mathrm{J} / \mathrm{kmol} . \mathrm{K}, \mathrm{MW}$ is the molecular weight of the fuel and $g_{c}$ is the gravitational constant equal to 1.0 $(\mathrm{kg} \cdot \mathrm{m}) /\left(\mathrm{N} . \mathrm{s}^{2}\right)$.

For subsonic conditions, the fuel mass flow rate is given by:

$m=c_{d} \ell_{e} A M_{e} c_{e}$

where

$$
\begin{aligned}
& M_{e}=\sqrt{\frac{2}{k-1}\left[\left(\frac{P_{t}}{P_{b}}\right)^{\frac{k-1}{k}}-1\right]} \\
& T_{e}=\frac{T_{t}}{1+\frac{k-1}{2} M_{e}^{2}} \\
& c_{e}=\left[\frac{k T_{E} R}{M W}\right]^{\frac{1}{2}} \\
& \ell_{e}=\frac{P_{b}}{\frac{T_{e} R}{M W}}
\end{aligned}
$$

The subscript, e, denotes the orifice exit, $M_{e}$ is the mach number of the fuel, $T_{e}$ is the temperature of the fuel, $c_{e}$ is the speed of sound in the fuel, and $\ell_{e}$ is the density of the fuel.

Design of the Venturi Section: Adiabatic compressible flow equations for an ideal gas are used in designing this section of the burner. The relationship between Mach number and velocity at the throat is given by Rajput (2003),

$$
M=\frac{V}{\sqrt{k R T}}
$$

where $c=\sqrt{k R T}$, is the sonic velocity.

The relationship between the critical throat area $A_{c}$, where the mach number is unity and the area $A$ at any section where the mach number may be greater than or less than 1 is given by:

$$
\frac{A}{A_{C}}=\frac{1}{M}\left[\frac{2+(k-1) M^{2}}{k+1}\right]^{\frac{k+1}{2(k-1)}}
$$

\section{Design calculations for the Burner}

Calculations for Burner Heat release and Gas Orifice: From the heat balance calculations for the furnace for which this burner is being developed, the fuel consumption of the furnace is, $\mathrm{B}=12.55 \mathrm{~kg} /$ period.

Which for a one hour period gives,

Mass flow rate of fuel $m=\frac{B}{1 \times 3600}=0.0035 \mathrm{~kg} / \mathrm{s}$

Heating value for butane, $\mathrm{Hv}=45800 \mathrm{~kJ} / \mathrm{kg}$

Therefore from equation (1), the burner heat release, $H R=0.0035 \times 45800=160.3 \mathrm{~kW}$

The critical pressure for the fuel is calculated from equation (2) as,

$$
P_{C}=\left[\frac{2}{1.1-1}\right]^{\frac{1.1}{1.1-1}}=0.585
$$

where, $\mathrm{k}=1.1$ for Butane, (Baukal,2004).

Assume standard atmospheric pressure $\left(P_{b}\right)=1.013$ bar and pressure of fuel, $\mathrm{P}_{\mathrm{t}}=1.7 \mathrm{bar}$, then

$$
\frac{P_{b}}{P_{t}}=0.595
$$

this is subsonic condition since $\mathrm{P}_{\mathrm{c}}<\mathrm{P}_{\mathrm{b}} / \mathrm{P}_{\mathrm{t}}$. The area of gas orifice can be determined from the gas mass flow rate equation (4).

$$
m=c_{d} \ell_{e} A M_{e} c_{e}
$$




$$
\begin{aligned}
& \text { where } \\
& \mathrm{m}=0.0035 \mathrm{~kg} / \mathrm{s} \\
& \mathrm{C}_{\mathrm{d}}=0.85
\end{aligned}
$$

From equations (5) to (7)

$$
\begin{aligned}
\mathrm{g}_{\mathrm{e}} & =2.35 \mathrm{~kg} / \mathrm{m}^{3} \\
\mathrm{M}_{\mathrm{e}} & =0.61 \\
\mathrm{~T}_{\mathrm{e}} & =277.83 \mathrm{k} \\
\mathrm{C}_{\mathrm{e}} & =209.31 \mathrm{~m} / \mathrm{s}
\end{aligned}
$$

Therefore area of orifice,

$$
A=\frac{0.0035}{0.85 \times 2.35 \times 0.61 \times 209.31}=1.37 \times 10^{5} \mathrm{~m}^{2}
$$

The diameter of orifice is,

$$
d_{o}=\sqrt{\frac{4 A}{\pi}}=0.004 m
$$

Take actual orifice diameter as $6 \mathrm{~mm}$

\section{Calculations for the Venturi section}

Using the theoretical air fuel ratio, the mass flow rate of air is:

$$
\begin{aligned}
& m_{a}=17.0 \times m \\
& m_{a}=17.0 \times 0.0035=0.060 \mathrm{~kg} / \mathrm{s}
\end{aligned}
$$

Dividing by density of air gives the volume flow,

$$
Q=0.05 \mathrm{~m}^{3} / \mathrm{s}
$$

A diameter of $28 \mathrm{~mm}$ is chosen for inlet and throat of burner, with a length

to diameter ratio of 7 ,length of throat is,

$$
L_{t}=7 \times 0.028=0.196 \mathrm{~m}
$$

area of burner throat,

$$
A_{t}=\pi \frac{(0.028)^{2}}{4}=6.2 \times 10^{-4} \mathrm{~m}^{2}
$$

Air velocity at throat,

$$
V_{t}=\frac{Q}{A_{t}}=\frac{0.05}{6.2 \times 10^{-4}}=81.2 \mathrm{~m} / \mathrm{s}
$$

Mach number at throat'
$M_{t}=\frac{V_{t}}{\sqrt{k R T}}=\frac{81.2}{\sqrt{1.4 \times 287 \times 573}}=0.169$

With this Mach number in the table of one dimensional isentropic relations

for air , the area ratio is

$$
\frac{A}{A_{t}}=3.48
$$

Therefore area at mixing tube end is,

$$
A=3.48 \times 6.2 \times 10^{-4}=2.2 \times 10^{-3} \mathrm{~m}^{2}
$$

from which the diameter is $d=0.054 \mathrm{~m}$.

\section{Downstream section and Burner tip}

For the down stream section the chosen diameter and length are $54 \mathrm{~mm}$ and $50 \mathrm{~mm}$ respectively while that for the burner tip are $42 \mathrm{~mm}$ and $75 \mathrm{~mm}$ respectively.

$\begin{array}{ll}\text { Design Specifications for Burner } & \\ \text { Fuel gas Orifice diameter } & 6 \mathrm{~mm} \\ \text { Throat diameter } & 28 \mathrm{~mm} \\ \text { Throat length } & 20 \mathrm{~mm} \\ \text { Mixing tube exit diameter } & 54 \mathrm{~mm} \\ \text { Mixing tube divergence angle } & 7^{\circ} \\ \text { Downstream section length } & 50 \mathrm{~mm} \\ \text { Downstream section diameter } & 54 \mathrm{~mm} \\ \text { Burner tip diameter } & 42 \mathrm{~mm} \\ \text { Burner tip length } & 75 \mathrm{~mm}\end{array}$

\section{Construction and Performance evaluation}

The designed burner was constructed using mild steel material. The nozzle, downstream section, mixing tube and throat were machined separately and threaded to make for ease of dismantling and assembling.

A $2.5 \mathrm{~cm}$ air valve is placed at the inlet section to control the air flow into the burner.

A cross-connected regulator is connected to the burner through the gas inlet nozzle on the burner. A pressure sensing line is run from the burner combustion air line to the regulator's gas valve while the gas hose from the gas cylinder is connected to the inlet of the regulator. The cross-connected regulator is designed to maintain a fuel outlet pressure that matches the combustion air. The high velocity air supply from a blower entrains fuel (gas) 
from the gas orifice which is introduced at the burner throat at an angle of $30^{\circ}$.

The cross-sectional and assembled views of the burner are shown in Figure 1.

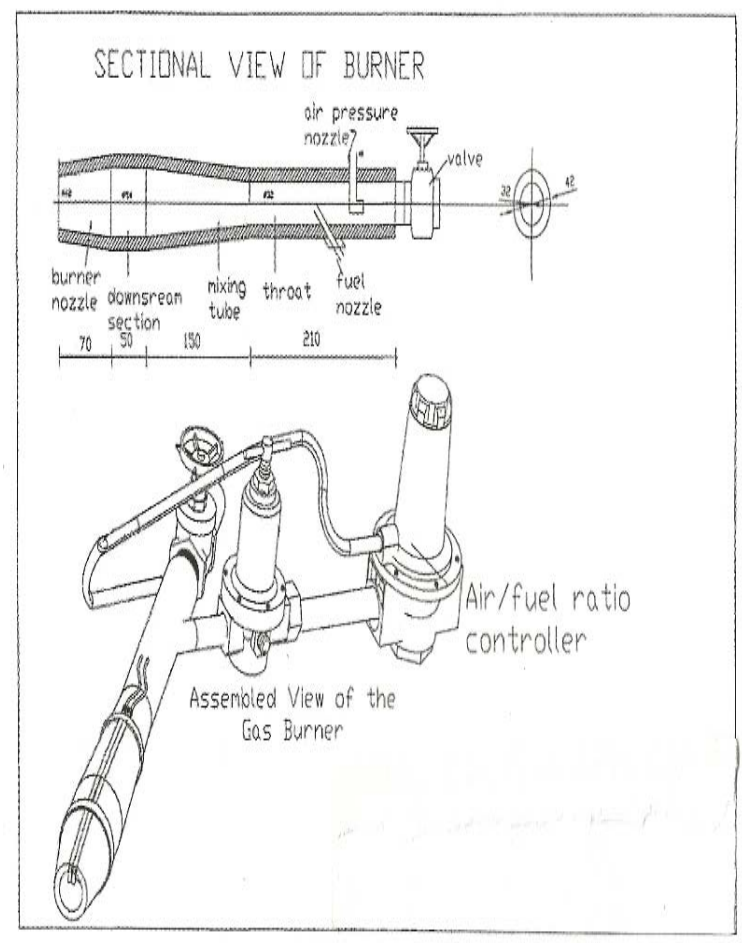

Fig. 1: Cross-sectional and assembled view of the Burner

\section{Test procedure}

The Burner was tested to determine its functionality. The following test procedure was followed.

1. The burner was connected to an air blower and the gas (butane) supply. The blower has a capacity of 0 to $5000 \mathrm{~m}^{3} / \mathrm{s}$ and rotative speed of 300 to $3000 \mathrm{rpm}$ (Cherkassy, 1985).

2. The burner was placed in a horizontal position on a measuring stand.

3. The burner was lit and the gas pressure maintained at $30 \% \quad(0.53$ bar $)$ corresponding to a flow rate of $1.68 \times 10^{-6}$ $\mathrm{m}^{3} / \mathrm{s}$. The corresponding air-flow rate was $5.72 \times 10^{-5} \mathrm{~m}^{3} / \mathrm{s}$.

4. The flame temperature was measured using an infra-red Thermometer (model 39800 , temperature range $0-1200{ }^{\circ} \mathrm{C}$ ), and a pyrometer/multi-tester (model HC$3500 \mathrm{~T}$, temperature range $0-2000{ }^{\circ} \mathrm{C}$ using fibre-glass coated k-type thermocouple), along the flame axis at distance of 0 to $45 \mathrm{~cm}$ from the burner tip in steps of $5 \mathrm{~cm}$.

5. The same procedure was carried out for gas pressures of $60 \%$ (1.02 bar), 90\% (1.53 bar) and 100\% (1.7 bar) corresponding to gas flow rates of $3.36 \mathrm{x}$ $10^{-6}, 5.04 \times 10^{-6}$, and $5.6 \times 10^{-6} \mathrm{~m}^{3} / \mathrm{s}$ respectively. The corresponding air flow rates are $1.12 \times 10^{-4}, 1.72 \times 10^{-4}, 1.91 \times$ $10^{-4}$ respectively.

\section{RESULT AND DISCUSSIONS}

The readings obtained from the measurements are as tabulated in

Table 1. A plot of temperature against flame axis distance is shown in Figure 2 for the gas pressures.

Table 1: Temperature values along flame axis at different gas pressures.

\begin{tabular}{|l|l|l|l|l|}
\hline \multirow{2}{*}{\begin{tabular}{l} 
Axial distance $\begin{array}{l}\text { along flame } \\
\text { axis }(\mathrm{cm})\end{array}$ \\
\cline { 2 - 5 }
\end{tabular}} & $\begin{array}{l}30 \% \\
(0.53 \text { bar })\end{array}$ & $\begin{array}{l}\text { Te\% } \\
(1.02 \text { bar })\end{array}$ & $\begin{array}{l}90 \% \\
(1.53 \text { bar })\end{array}$ & $\begin{array}{l}100 \% \\
(1.7 \text { bar })\end{array}$ \\
\hline 0 & 219.0 & 346.4 & 469.1 & 70 \\
\hline 5 & 373.7 & 550.6 & 737.0 & 1231.0 \\
\hline 10 & 383.3 & 561.8 & 841.4 & 1275.0 \\
\hline 15 & 453.6 & 607.2 & 853.2 & 1220.0 \\
\hline 20 & 488.1 & 688.8 & 935.5 & 1175.0 \\
\hline 25 & 454.9 & 669.6 & 960.3 & 1171.0 \\
\hline 30 & 450.8 & 519.8 & 901.7 & 1130.0 \\
\hline 35 & 340.8 & 499.2 & 831.3 & 1088.0 \\
\hline 40 & 306.6 & 472.2 & 703.4 & 902.0 \\
\hline 45 & 305.4 & 424.8 & 653.8 & 605.0 \\
\hline
\end{tabular}


Am. J. Sci. Ind. Res., 2011, 2(1): 49-53

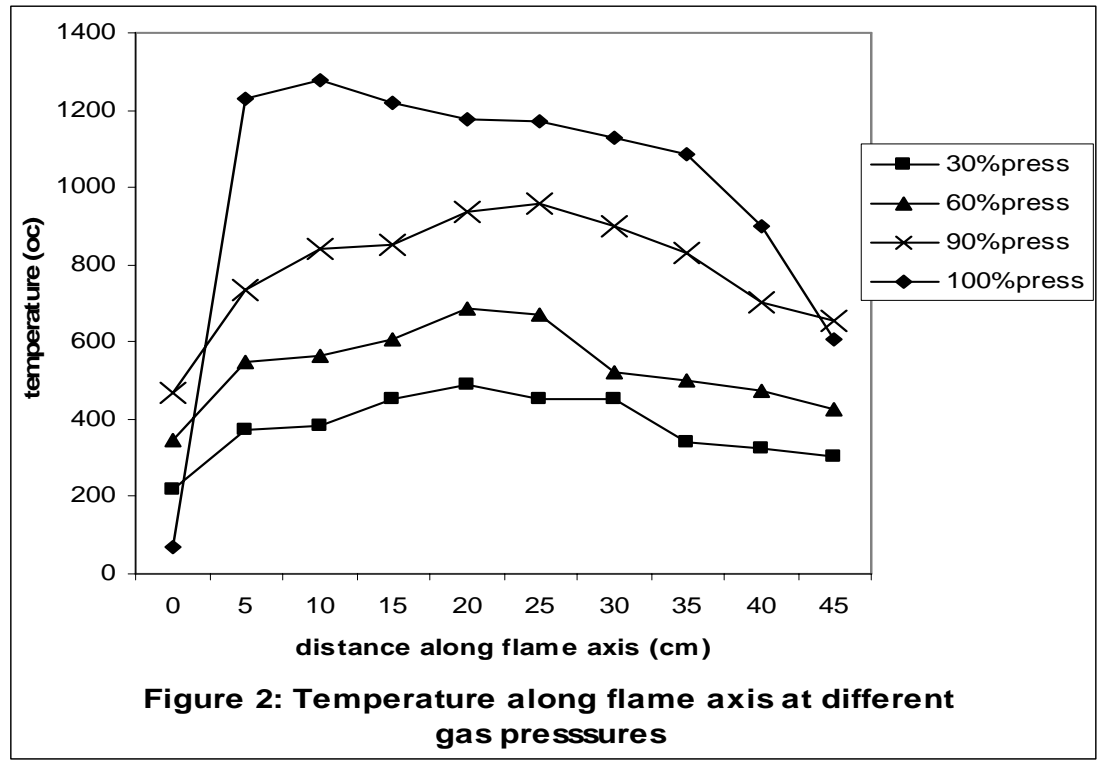

It can be observed from Table 1 and the graph plotted that higher temperatures were obtained as the gas pressure (flow rate) was increased. The highest temperatures recorded were 488.1, 688.8960 .3 and $1275{ }^{\circ} \mathrm{C}$ for gas pressures at $30,60,90$ and $100 \%$ respectively.

The flame temperatures increased gradually from the burner tip to a maximum at a distance of $20 \mathrm{~cm}$ for both $30 \%$ and $60 \%$ gas pressures, $25 \mathrm{~cm}$ and $10 \mathrm{~cm}$ for 90 and $100 \%$ gas pressures respectively and then started falling again. The burner tip to the point of maximum temperature corresponded to the zone of intense heat and the flame was completely blue in this zone. It was observed that the yellow portion of the flame had become reduced and the flame became almost completely blue at $90 \%$ and $100 \%$ gas pressures. The temperatures attained by the burner shows that it can be used for high temperature Furnace applications such as non-ferrous metal melting, metal heat treatment and reheating etc. For an open flame test, there is a diluting effect on the temperature by the atmospheric air, it is therefore expected that higher temperatures can be obtained when firing is done in an enclosure.

\section{CONCLUSION:}

An industrial high velocity burner has been developed and tested. The test conducted shows that it can be employed for high temperature Furnace applications such as is found in metal processing industries. The test conducted was an open flame test. It is expected that higher temperatures can be obtained when the burner is fired in an enclosure.

\section{REFERENCES}

Baukal, C.E Jr (2004). Industrial Burner Handbook. Florida: CRC press, 790pp.

Baukal, C.E. Jr.; Gershtein, V.Y. and Li, X. (2001). Computational Fluid Dynamics in Industrial Combustion. U.S.A.:CRC press, 630pp.

Cherkassky, V.M. (1985). Pumps, Fans, Compressors. Moscow: Mir publishers. 388pp

Gilchrist, J.D. (1977). Fuel, Furnaces and Refractories: Pergamon press, 380pp.

Rajput, R.P. (1998). A Textbook of Fluid Mechanics. India: Chand \& Company Ltd., 876pp.

Trinks, W. and Mawhinney, M.H. (1967), Industrial furnaces, Vol. II, $4^{\text {th }}$ ed. U.S.A: John Wiley and sons Inc.

356pp. 